\title{
Fast photovoltaic IncCond-MPPT and backstepping control, using DC-DC boost converter
}

\author{
Mohamed Moutchou ${ }^{1}$, Atman Jbari ${ }^{2}$ \\ ${ }^{1}$ Department of Electrical Engineering, National Higher School of Arts and Crafts, \\ Hassan II University in Casablanca, Morocco \\ ${ }^{2}$ Electronic Systems, Sensors and NanoBiotechnology Research Group, Higher school of Technical Education, \\ Mohammed V University in Rabat, Morocco
}

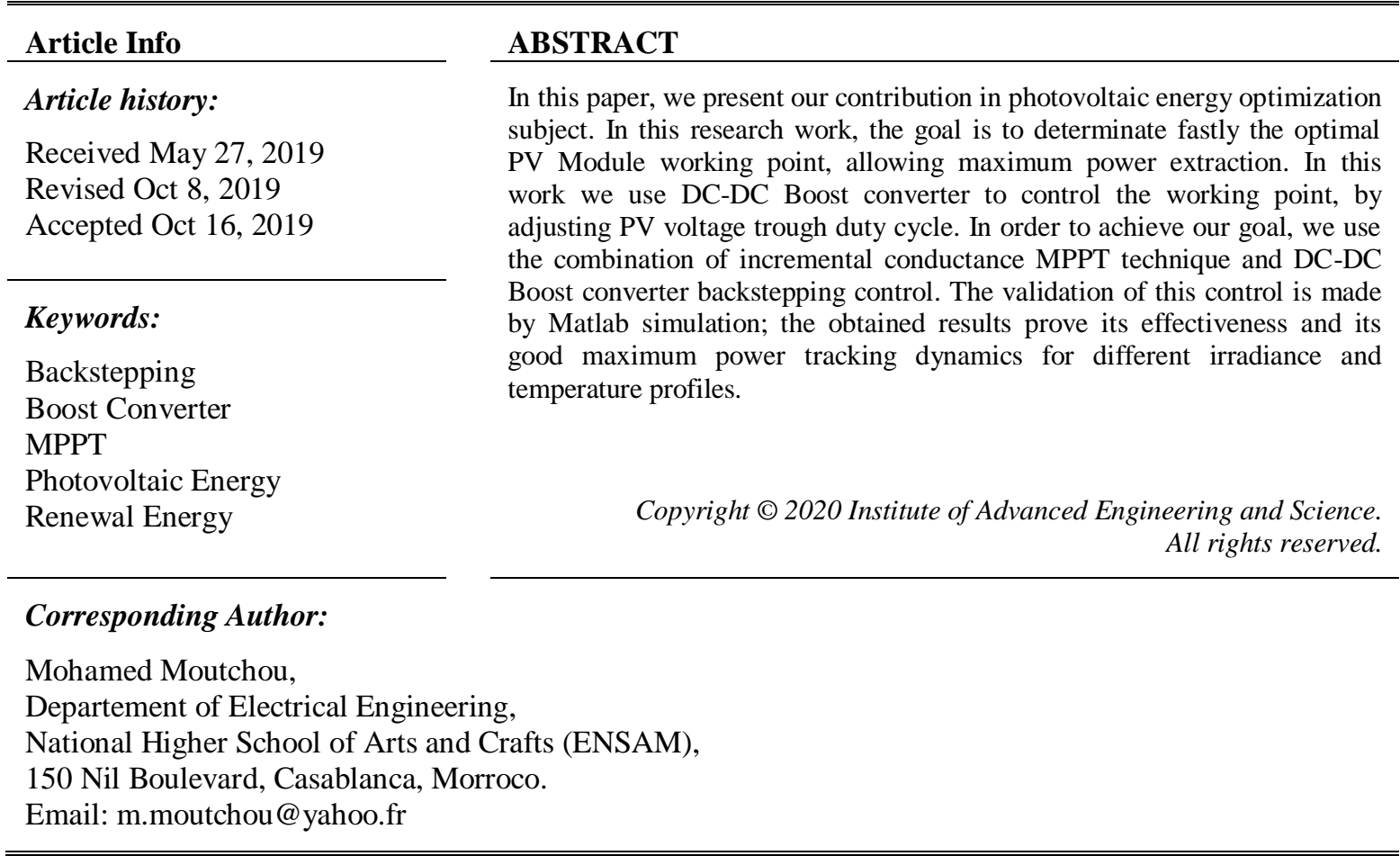

\section{INTRODUCTION}

Nowadays, for ecological and economic reasons, renewable energies have attracted a lot of interest from different political, economic and governmental actors and in particular from the community of scientific researchers. At our national level, since November 2009, Morocco adopts an energy strategy based in particular on renewable energies, setting itself to reach in $2020,42 \%$ of installed power based on renewable energy, and 52\% in 2030, by launching megaprojects in areas related to solar and wind energy. Photovoltaic power generation is currently expanding, but it accounts for only $1.9 \%$ of global electricity production worldwide, as showen in Figure 1 (end of 2017) [1]. Photovoltaic energy presents several challenges because of its intermittent and variable nature during the day and from one season to another.

Scientific Researchers try through their researches to make the use and conversion of these energies more efficient, profitable, competitive and therefore more interesting. The primary concern of the researchers is to increase the efficiency of the PV energy conversion operation by implementing high performance MPPT algorithms and the design of efficient energy converter structures. There are about twenty methods for tracking the Maximum Power Point (MPPT), whose efficiency and speed vary. The most commonly encountered methods are [2]:

- Hill-Climbing and P \& O (Perturb and Observe). These two methods are too close, they work on the same principle which consists in disrupting the functioning of the system and then analyzing how the system reacts to this disturbance (Hill-Climbing react on the hash duty cycle, while P\&O make change in PV output voltage) [3-10]. 
- The IncCond (Incremental Conductance) method which consists in comparing the incremental conductance with instantaneous conductance, in order to determine the working point position on powervoltage curve, and make a correct decision function of used converter kind [11-16].

- The (FOC) Fractional Open-Circuit Voltage method, based on the proportionality between the open circuit voltage (Voc) and the voltage at the maximum power point (Vmpp).

- The (FSC) Fractional Short-Circuit current method based on the proportionality between the short-circuit current (Isc) and the current at the maximum power point (Impp).

In this research we choose to use the IncCond MPPT technique principle for designing our MPPT control based on Boost structure for DC-DC conversion. In order to achieve good control performance, in term of dynamics and precision, we used the backstepping technique [17-22] for the control design of the DC-DC Boost converter. In first, we present de PV Module Model with one diode and its behavior for variation of radiation and temperature, next in third section the DC-DC Boost converter model used in this work, then in section 4, we present the DC-DC Boost converter control design using backstepping technique, after that in section 5, we present our MPPT technique based on the principle of Incremental conductance, finally sixth section we give simulation results of the PV conversion control, followed by conclusion.

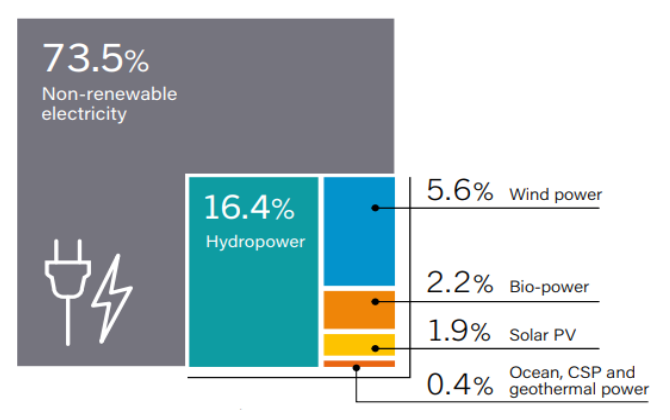

Figure 1. Estimated renewable energy share of global electricity production, end-2017 [1]

\section{MODEL OF PHOTOVOLTAIC MODULE}

The cell consists of a PN junction. A specific coating is applied on the upper face to improve the yield. Collectors collect the charge carriers. When a photon has sufficient energy to pass an electron from the valence band to that of conduction, an electron-hole pair is created. Then thanks to the internal electric field of the depletion zone, the separation of the electrons-holes is carried out, and consequently the creation of a potential difference. In this research we use the single diode equivalent circuit model as showing in Figure 2, to simulate PV Module voltage-current (V-I) behavior. The main model parameters comprise the photogenerated current $(I \mathrm{ph})$, saturation current $(I \mathrm{ss})$, diode ideality factor $(\eta)$. series resistance $(R s)$ and shunt resistance $(R \mathrm{p})$ [23-25]. These parameters values are given in Table 1.

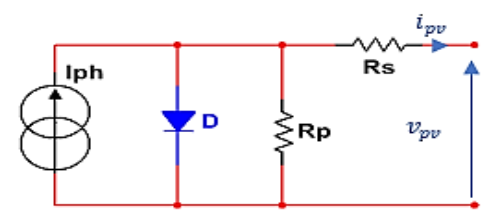

Figure 2. PV module model

In this model the output current can be expressed as follows:

Where:

$$
i_{p v}=i_{p h}-I_{s S} *\left(\exp \left(\frac{v_{p v}-R_{S} * i_{p v}}{\eta * v_{T h}}\right)-1\right)-\frac{v_{p v}-R_{S} * i_{p v}}{R_{p}}
$$

- $\quad v_{T h}=\frac{k * T}{q}:$ is the thermal voltage of PN junction

- $\mathrm{q}$ : is the elementary charge $\left(q=1,602.10^{-19} c\right)$

- $\mathrm{k}$ : is the Boltzmann constant $\left(k=1,38 \cdot 10^{-23} J \cdot K^{-1}\right)$ and T: is the Temperature (in Kelvin) 
To use, and solve (1), we have designed solver algorithm based on Raphson-Newton. The saturation current $I_{s S}$ can be determined by following equation:

$$
I_{S S}=\frac{I_{S c N}+K_{i} *\left(T-T_{N}\right)+\frac{V_{o c N}+K_{v} *\left(T-T_{N}\right)}{R_{p}}}{\exp \left(\frac{V_{o c N}+K_{v} *\left(T-T_{N}\right)}{a * V_{t h}}\right)-1}
$$

The photogenerated current $i_{p h}$ and open circuit voltage $v_{o c}$ can be calculated from rated parameters value of the PV module, as follows:

Where:

$$
\begin{aligned}
& i_{p h} \approx I_{s c}=\left(\frac{G}{G_{N}}\right) *\left(I_{s c N}+K_{i} *\left(T-T_{N}\right)\right) \\
& V_{o c}=V_{o c N}+K_{v} *(T-T N)
\end{aligned}
$$

- $\mathrm{G}:$ is the irradiance (in $W / \mathrm{m}^{2}$ )

- $G_{N}:$ is the irradiance for standard test conditions.

- $\quad \mathrm{T}$ : is the temperature (in $\mathrm{K}$ )

- $\quad T_{N}$ : is the temperature for standard test conditions.

- $I_{s c}:$ is the short circuit current (in A)

- $\quad I_{s c N}, V_{o c N}, K i$ and $K v$ are given below in Table 1 .

Table 1. The PV module parameters

\begin{tabular}{llcc}
\hline Parameters & & Values & Units \\
\hline Nominal Power & Pc & 60 & $\mathrm{w}$ \\
Open-Circuit Voltage & Voc & 21.1 & $\mathrm{~V}$ \\
Short-Circuit Voltage & $\mathrm{Isc}$ & 3.8 & $\mathrm{~A}$ \\
Rated Voltage & $\mathrm{Vmpp}$ & 17.1 & $\mathrm{~V}$ \\
Rated Current & $\mathrm{Impp}$ & 3.5 & $\mathrm{~A}$ \\
Current Temperature Coefficients & $\mathrm{ki}$ & 2.5 & $\mathrm{~mA} / \mathrm{K}$ \\
Voltage Temperature Coefficients & $\mathrm{kv}$ & -0.08 & $\mathrm{~V} / \mathrm{K}$ \\
Serie Resistance & $\mathrm{Rs}$ & 0.18 & $\Omega$ \\
Parallel Resistance & $\mathrm{Rp}$ & 360 & $\Omega$ \\
Ideality Factor & $\eta$ & 1.36 & \\
\hline
\end{tabular}

In order to illustriat the PV model behaviuour, we present below in Figure 3 to Figure 6, the currentvoltage and power-voltage curves of the model in case of various irradiation value with constante temperature as shown in Figure 3 and Figure 4, and in case of various value of temperature with constante irriation value as shown in Figure 5 and Figure 6.

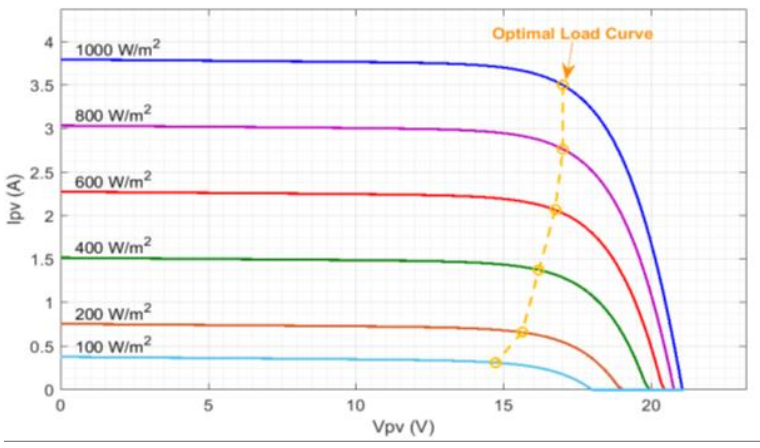

Figure 3. Ipv-Vpv PV Module curves for temperature $\mathrm{T}=25^{\circ} \mathrm{C}$, and for different irradiance values

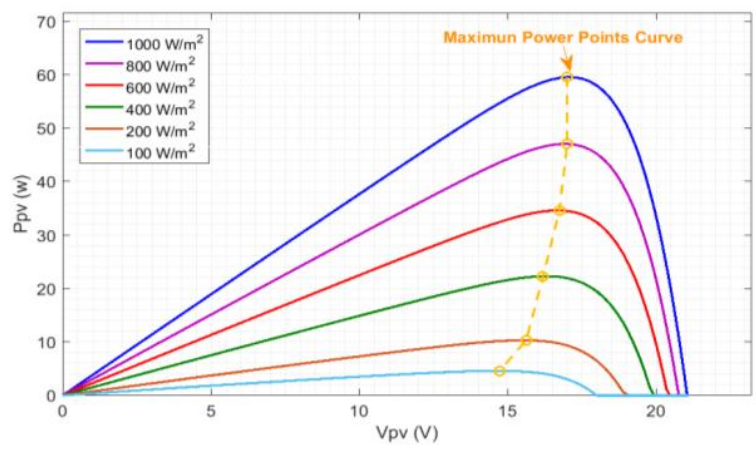

Figure 4. Ppv-Vpv PV Module curve for temperature $\mathrm{T}=25^{\circ} \mathrm{C}$, and for different irradiance values 


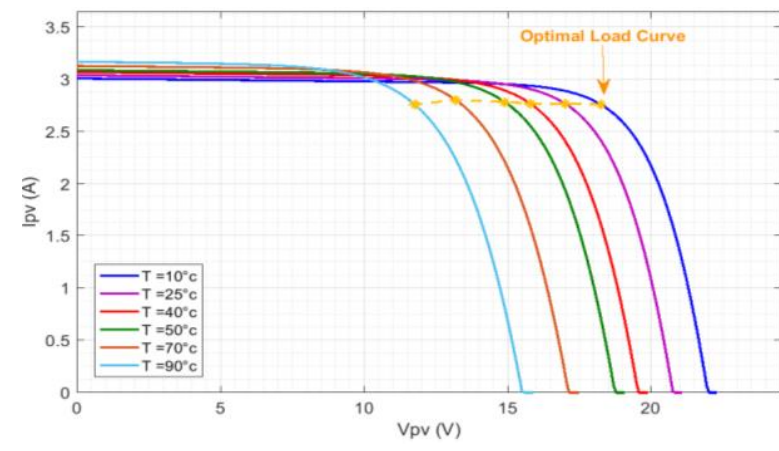

Figure 5. Ipv-Vpv PV Module curves for irradiance $\mathrm{E}=800 \mathrm{~W} / \mathrm{m}^{2}$, and for different temperature values

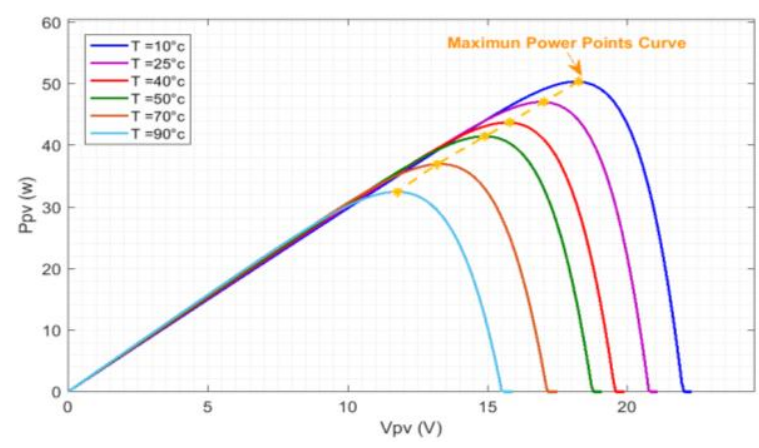

Figure 6. Ppv-Vpv PV Module curves for irradiance $\mathrm{E}=800 \mathrm{~W} / \mathrm{m}^{2}$, and for different temperature values

\section{DC-DC BOOST CONVERTER MODEL}

In this work, we choose to use DC-DC Boost converter to achieve load adaptation in order to make PV Module work at its maximum power point. We consider that this converter is more adequate for PV-MPPT control, because it allows us controlling input voltage $v_{e}$, that is equal to PV Module voltage $v_{p v}$ [26-27]. As showing Figure 7, the DC-DC Boost converter is composite of LC filter (L1, C1) for filtering input voltage $\left(v_{e}\right)$ and for decreasing current ripple of $i_{1}$, a switch (T), a diode (D), a capacitor (C2) and resistance load $(\mathrm{R})$. The parameters values used, are given in Table 2. The switch component $\mathrm{T}$ is commuted periodically as described below:

$\{T$ is On, for $t \in[0, \alpha T]\}$

$\{T$ is Off, for $t \in[\alpha T, T]\}$

Where $\alpha:$ is a duty cycle

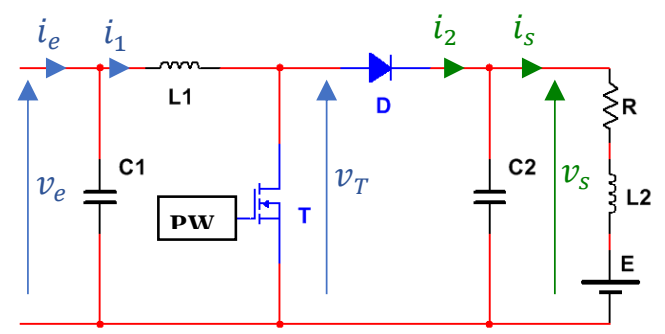

Figure 7. Boost converter scheme

Table 2. Boost Dc-Dc converter parameters

\begin{tabular}{llcc}
\hline Parameters & & Values & Units \\
\hline Input Capacitor & $\mathrm{C} 1$ & 1000 & $\mu F$ \\
Output Capacitor & $\mathrm{C} 2$ & 470 & $\mu F$ \\
Input Inductance & $\mathrm{L} 1$ & 20 & $\mathrm{mH}$ \\
Switching Frequency & $\mathrm{F}$ & 20 & $\mathrm{kHz}$ \\
\hline
\end{tabular}

The equations that describe the DC-DC Boost Converter are given below:

$$
\left\{\begin{array}{l}
\frac{d v_{e}}{d t}=\frac{1}{C_{1}} \cdot\left(i_{e}-i_{1}\right) \\
\frac{d i_{1}}{d t}=\frac{1}{L} \cdot\left(v_{e}-v_{T}\right) \\
\frac{d v_{s}}{d t}=\frac{1}{C_{2}} \cdot\left(i_{2}-i_{s}\right)
\end{array}\right.
$$


For $t \in[0, \alpha T]$, we have:

$\mathrm{T}$ is $\mathrm{ON} \rightarrow v_{T}=0 \rightarrow \mathrm{D}$ is Off $\rightarrow i_{2}=0$.

For $t \in[\alpha T, T]$, we have; $\mathrm{T}$ is $\mathrm{OFF} \rightarrow \mathrm{D}$ is $\mathrm{On} \rightarrow v_{T}=v_{S} \rightarrow i_{2}=i_{1}$.

Then the Boost converter averaging model is as below:

$$
\left\{\begin{array}{c}
\frac{d v_{e}}{d t}=\frac{1}{C_{1}} \cdot\left(i_{e}-i_{1}\right) \\
\frac{d i_{1}}{d t}=\frac{1}{L} \cdot\left(v_{e}-v_{s} \cdot(1-\alpha)\right) \\
\frac{d v_{s}}{d t}=\frac{1}{C_{2}} \cdot\left(i_{1} \cdot(1-\alpha)-i_{s}\right)
\end{array}\right.
$$

\section{BOOST CONVERTER BACKSTEPPING CONTROL}

In this section we will give the study that allows determining control law of the Boost converter offering desired performances. This control will help us to achieve the mean goal, which is the extraction of maximum photovoltaic power. The control will be designed in two successive steps, and through a virtual variable command. This control will be used to adjust output PV voltage in order to perform maximum power tracking.

\subsection{First step: input variable control}

In this step we design the control that ensure the good $v_{e_{r e f}}$ tracking by $v_{e}$, so we define below the tracking error:

$$
e_{1}=v_{e_{\text {ref }}}-v_{e}
$$

The error dynamic is given by:

$$
\begin{aligned}
& \dot{e}_{1}=\dot{v}_{e_{\text {ref }}}-\dot{v}_{e} \\
& \dot{e}_{1}=\dot{v}_{e_{\text {ref }}}-\frac{i_{e}}{C_{1}}+\frac{i_{1}}{C_{1}}
\end{aligned}
$$

To ensure the first step control stability, we chose the first Lyapunov Candidate Function (LCF) as following:

$$
w_{1}=\frac{1}{2} \cdot e_{1}^{2}
$$

The LCF dynamic is given below:

$$
\begin{aligned}
& \dot{w}_{1}=e_{1} \cdot e_{1} \\
& \dot{w}_{1}=e_{1} \cdot\left(\dot{v}_{e_{r e f}}-\frac{i_{e}}{C_{1}}+\frac{i_{1}}{C_{1}}\right)
\end{aligned}
$$

In order to have $\dot{w}_{1}<0$, we chose the following control law:

$$
\dot{e_{1}}=-k_{1} \cdot e_{1}
$$

where $\mathrm{k} 1$ is a positive constant.

From (7) and (9) we can see that:

$$
\dot{w}_{1}=-k_{1} \cdot e_{1}^{2}<0
$$


From (8) and (9) we obtain the following equation:

$$
-k_{1} \cdot e_{1}=\dot{v}_{e_{r e f}}-\frac{i_{e}}{C_{1}}+\frac{i_{1}}{C_{1}}
$$

We consider the following virtual variable command $\alpha$, ensuring first step stability:

$$
\alpha=\frac{i_{1}}{C_{1}}
$$

In order to have a stable tracking error dynamic, we impose the following reference control:

$$
\alpha_{\text {ref }}=-k_{1} \cdot e_{1}-\dot{v}_{e_{r e f}}+\frac{i_{e}}{C_{1}}
$$

\subsection{Second step: virtual variable control}

In this step we try to stabilize the tracking error of the following virtual command:

$$
e_{2}=\alpha_{\text {ref }}-\alpha
$$

After derivation we yields the following dynamic equations of virtual control error $e_{2}$ :

$$
\begin{aligned}
& \dot{e}_{2}=\dot{\alpha}_{\mathrm{ref}}-\dot{\alpha} \\
& \dot{e}_{2}=\dot{\alpha}_{r e f}-\frac{1}{L \cdot C_{1}} \cdot\left(v_{e}-v_{s} \cdot(1-\alpha)\right)
\end{aligned}
$$

Be the following CLF of global control:

$$
w_{2}=\frac{1}{2} \cdot e_{1}^{2}+\frac{1}{2} \cdot e_{2}^{2}
$$

After derivation we obtain:

$$
\dot{w}_{2}=-k_{1} \cdot e_{1}^{2}-e_{2} \cdot e_{1}+e_{2} \cdot \dot{e_{2}}
$$

We can make $\dot{w}_{2}$ negative definite, by choosing the following control law:

$$
-k_{2} \cdot e_{2}^{2}=-e_{2} \cdot e_{1}+e_{2} \cdot \dot{e_{2}}
$$

Where $\mathrm{k} 2$ is a positive constant.

So, we have to impose this following control law:

$$
\dot{e_{2}}=-k_{2} \cdot e_{2}+e_{1}
$$

By using (10) and (11) we determine, below, the expression of control ensuring the stabilization of the Boost converter control:

$$
\alpha=1-\left[\frac{L \cdot C_{1}}{v_{s}} \cdot\left(-k_{2} \cdot e_{2}+e_{1}-\dot{\alpha}_{r e f}\right)+\frac{v_{e}}{v_{s}}\right]
$$

\section{MAXIMUM POWER POINT TRACKING ALGORITHM}

In this research we chose to use incremental conductance technique to perform MPPT. It is characterized by a good and fast tracking, and presents lower power ripple when reaching maximum power point, in comparison with other technique like P\&O. The IncCond algorithm track MPP by determining the actual position of working point. The slope of the PV Module power curve can be calculated as: 


$$
\frac{d p}{d v}=\frac{d(v \cdot i)}{d v}=i+v \cdot \frac{d i}{d v}
$$
curve.

By considering the slope of the PV Module power curve, we distinguish tree different parts of this

Part1: When slope is positive the working point is at the left side of MPP: $\frac{d p}{d v}>0 \Rightarrow \frac{d i}{d v}>-\frac{i}{v}$

Part2: At MPP the slop is zero: $\frac{d p}{d v}=0 \Rightarrow \frac{d i}{d v} 0-\frac{i}{v}$

Part3: the slope is negative on the right side: $\frac{d p}{d v}<0 \Rightarrow \frac{d i}{d v}<-\frac{i}{v}$

The comparison between instantaneous conductance term $\left(\frac{i}{v}\right)$ and the incremental conductance term $\left(\frac{d i}{d v}\right)$ is used to determine the reference voltage at which the PV Module is forced to operate, in order to increase power and reach the MPP. At MPP the Vref will be equal to MPP voltage value (Vmpp), and the operating point is maintained, until a change in current $\Delta i$ or in voltage $\Delta v$ is detected. Those changes will indicate a change in atmospheric conditions or in load, in this case the algorithm will begin again the MPP search, as illustrated in Figure 8. The flowchart given in Figure 8, presents the IncCond MPPT principle, that we used to elaborate our MPPT Algorithm.

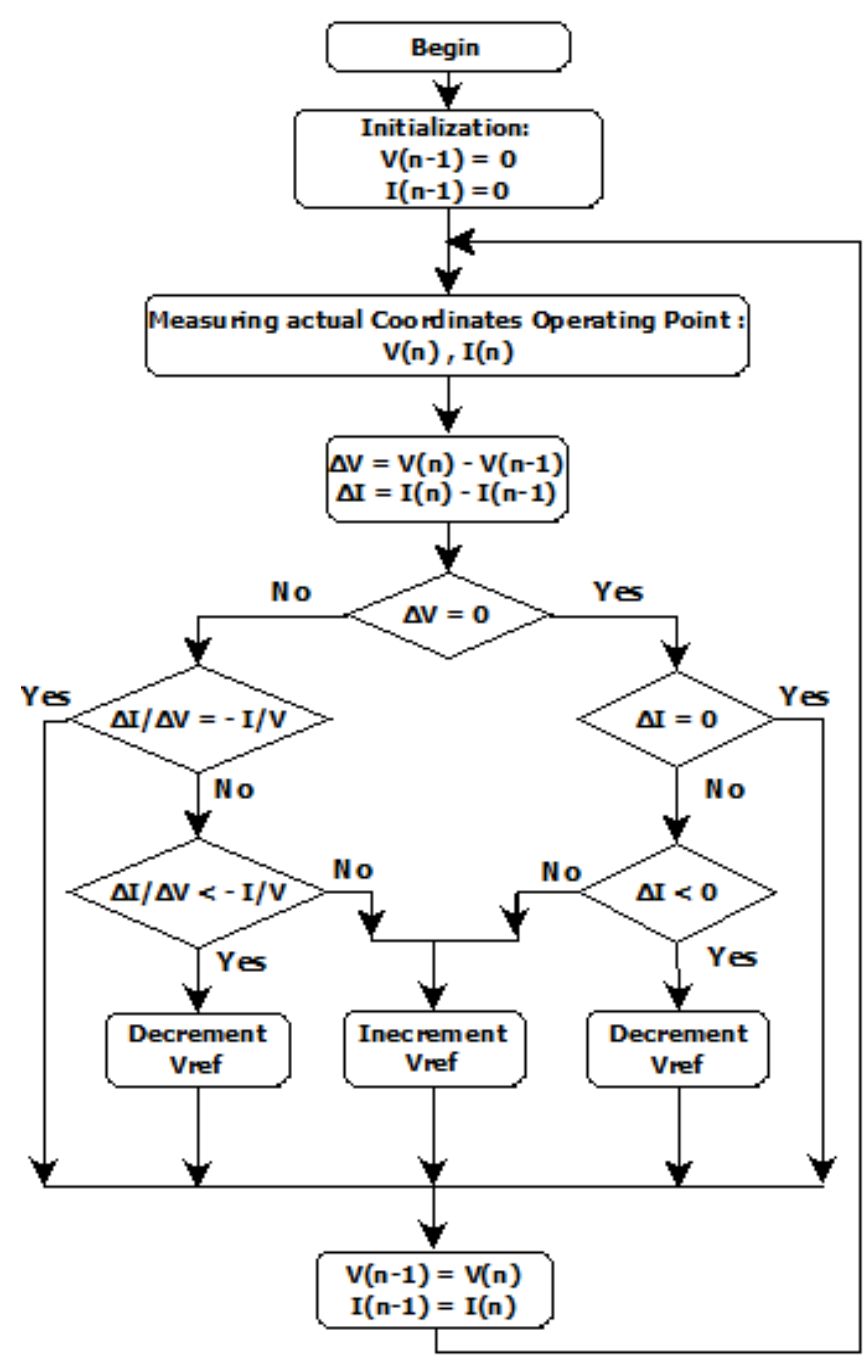

Figure 8. The incremental conductance flowchart 
But for better performance we have taking some improvement change, that we summarize in fore important points:

- In order to have a precise and fast MPP tracking, we must correctly choose the step of Vref increasing and decreasing. In this work we take a constant step equal to 0.2 .

- As the calculation duration is very important will implementing control, we have choosing to reduce it, by executing the MPPT algorithm periodically every thousand sampling period.

- We know that even at MPP we have no null voltage and current ripples, then for testing if they are a change in load or atmospheric conditions, we must take into a account the voltage and current ripples margins. So, we consider that there is no change while $|\Delta v|<\epsilon_{\Delta v}$ and $|\Delta i|<\epsilon_{\Delta i}$. In this research we take $\epsilon_{\Delta v}=10^{-5} \mathrm{~V}$ and $\epsilon_{\Delta i}=10^{-8} A$.

- $\quad$ At the end we must verify that $V_{r e f}$ still in a valid voltage interval $\left(v_{r e f} \in\left[0, V_{o c}\right]\right)$.

\section{SIMULATION RESULTS}

In this section we present the validation of our PV conversion control, whose structure is given in Figure 9. In order to verify the effectiveness of the adopted solution, we have performed a set of simulation tests. The control validation is made, in first with a load of type Resistance as shown in figures of the section (6.1), and in second with a type load of series association of resistance, inductance and voltage RLE as shown as shown in figures of the section (6.2).

In case of resistance load kind, it is essential to determine its value limits, that ensure having the working possibility at power maximum point of PV module. So, we determine in first, as showing in Figure 10 and Figure 11, the optimal load of PV module for different values of irradiance and temperature, which are taken respectively in following intervals: $[200,1000 \mathrm{~W} / \mathrm{m} 2]$ and $\left[10,90^{\circ} \mathrm{C}\right]$. This calculation leads to the determination of two optimal load extremum values $\left(R_{\text {opt_Max }}=25.4 \Omega\right.$ and $\left.R_{\text {opt_Min }}=3.5 \Omega\right)$, Obtained respectively for:

- $\mathrm{G}=200 \mathrm{~W} / \mathrm{m}^{2}$ and $\mathrm{T}=10^{\circ} \mathrm{C}$.

- And $\mathrm{G}=1000 \mathrm{~W} / \mathrm{m}^{2}$ and $\mathrm{T}=90^{\circ} \mathrm{C}$.

The determination of dc-dc converter optimal load $R_{\text {Load_opt }}$ is made by considering the steady stat of converter. When can establish following equation that represent $R_{\text {Load_opt }}$ in function of duty cycle $(\alpha)$ and $R_{\text {opt }}$ (optimal load at PV Module output):

$$
R_{\text {Load_opt }}=\frac{1}{(1-\alpha)^{2}} \cdot R_{\text {opt }}
$$

From Figure 12, we can see that resistance of load must be at less equal to $25.4 \Omega$. In the first simulation we use a purely resistive charge (with: $\mathrm{R}=50 \Omega, \mathrm{L}=0 \mathrm{H}$ and $\mathrm{E}=0 \mathrm{~V}$ ). The validation of the MPPT and Boost Control, is made by simulation, allowing control performances evaluation in case of hard changes profile of irradiance as showing in Figure 13 and of temperature as showing in Figure 14.

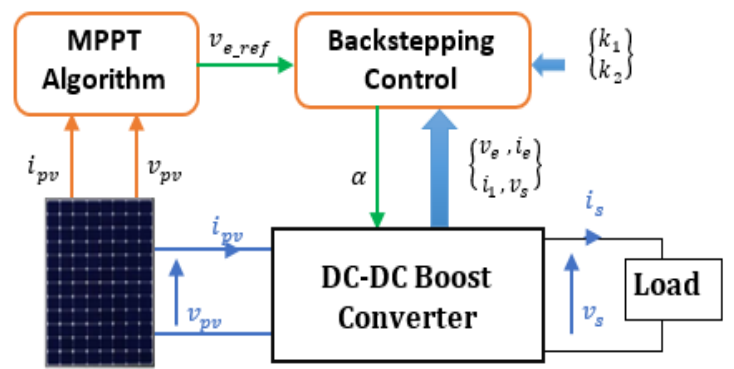

Figure 9. Structure of the MPPT-Backstepping control

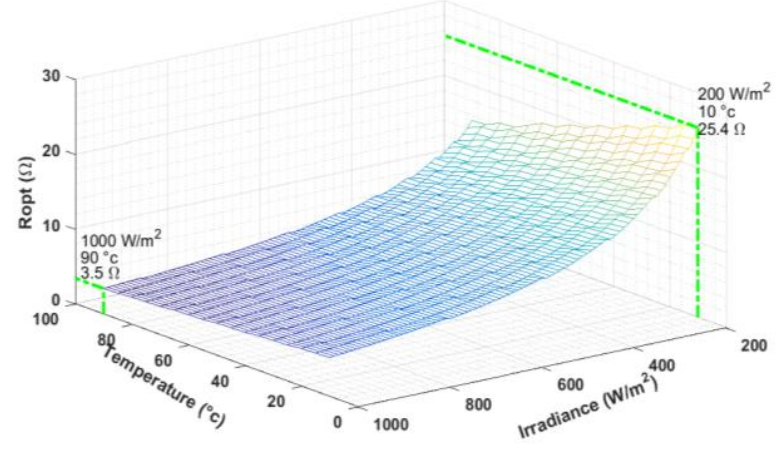

Figure 10. Ropt=f(T,G) Optimal Load Surface of PV Module for Irradiance $\mathrm{G} \in\left[2001000 \mathrm{~W} / \mathrm{m}^{2}\right]$ and Temperature $\mathrm{T} \in\left[1090{ }^{\circ} \mathrm{C}\right]$ 


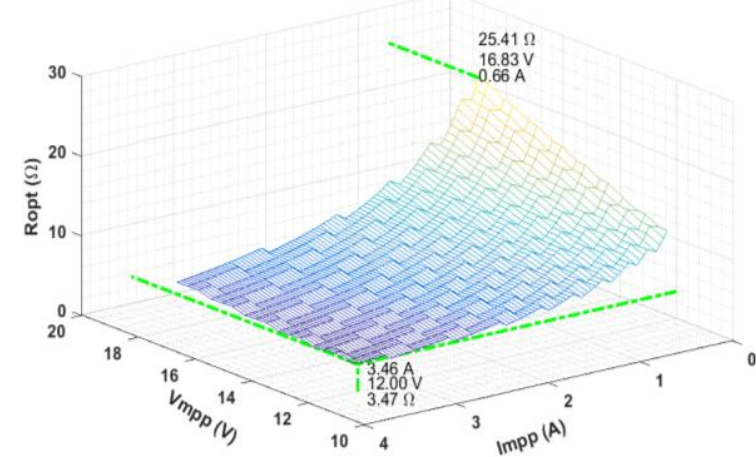

Figure 11. Ropt=f(Vmpp,Impp) Optimal Load Surface of PV Module for $\mathrm{G} \in[2001000 \mathrm{~W} / \mathrm{m} 2]$ and $\mathrm{T} \in\left[1090^{\circ} \mathrm{C}\right]$

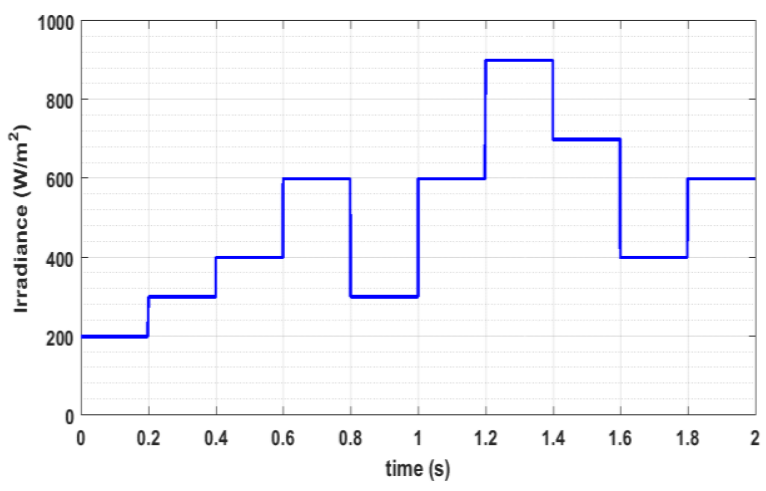

Figure 13. Irradiance Profile

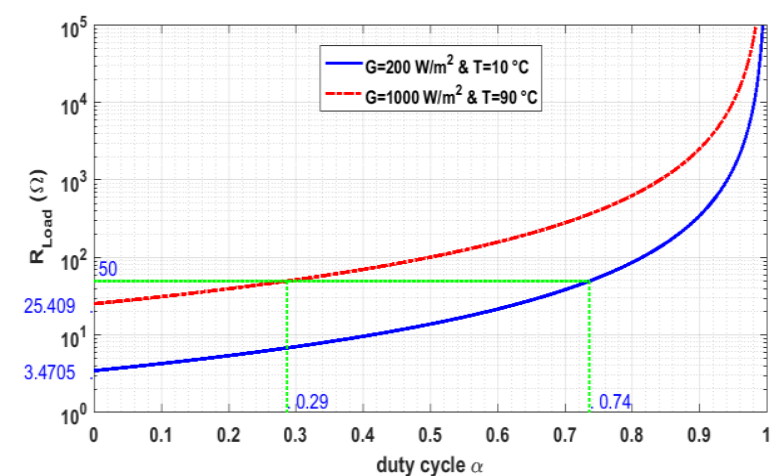

Figure 12. Curve of Resistance Load allowing optimal working

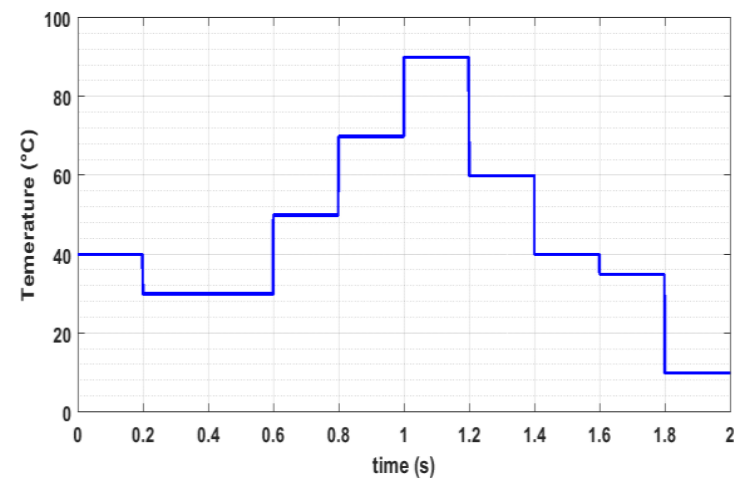

Figure 14. Temperature Profile

\subsection{Simulation in case of resistance load type $(R=50 \Omega)$}

We can see in Figure 15 that the control ensures a fast and precise tracking of maximum power of PV Module. In Figure 16 we present duty evolution that is determined by the backstepping control, based on voltage reference given by MPPT algorithm. Figure 17 shows that PV voltage track correctly the reference voltage. Figure 18 and Figure 19, present respectively the PV and inductance currents and output voltage. Its show that ripples don't exceed $10 \%$ with short duration that doesn't exceed 0.05 seconds, these ripples represent the MPP research phase. We notate that the ripples currents and voltage are null at steady state (when MPP is reach).

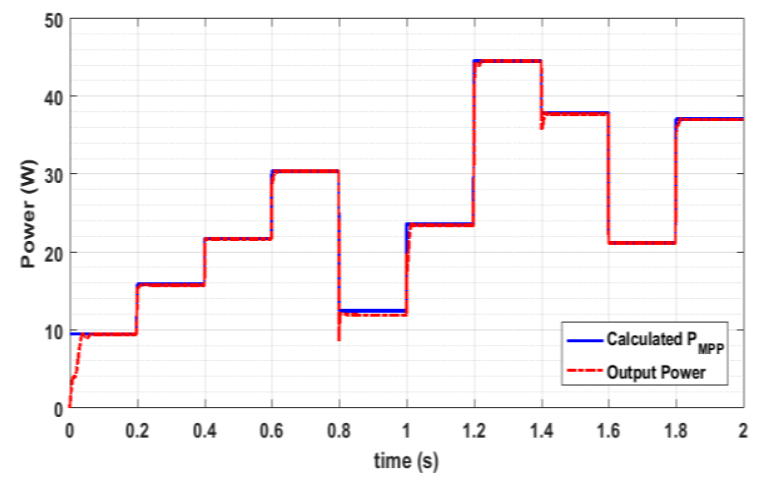

Figure 15. DC-DC Converter Output Power for $\mathrm{R}=50 \Omega$

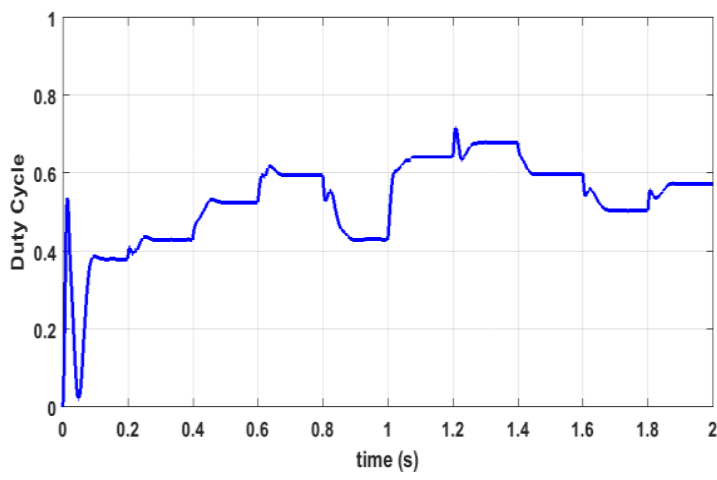

Figure 16. DC-DC Converter Duty Cycle for $\mathrm{R}=50 \Omega$ 


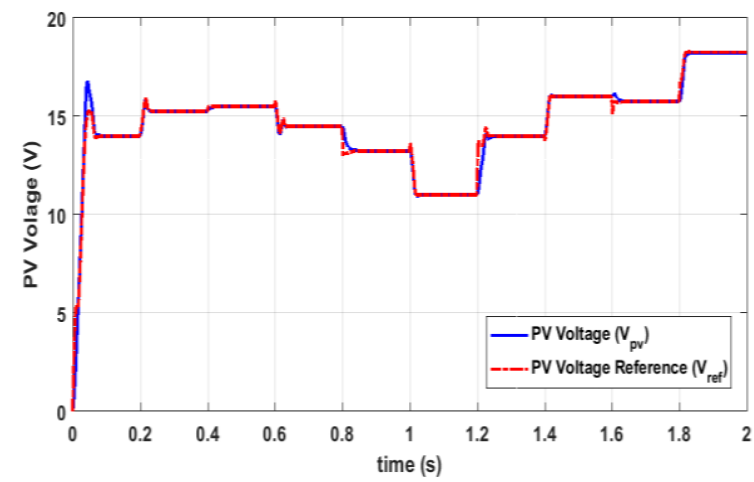

Figure 17. PV and Reference Voltages for $\mathrm{R}=50 \Omega$

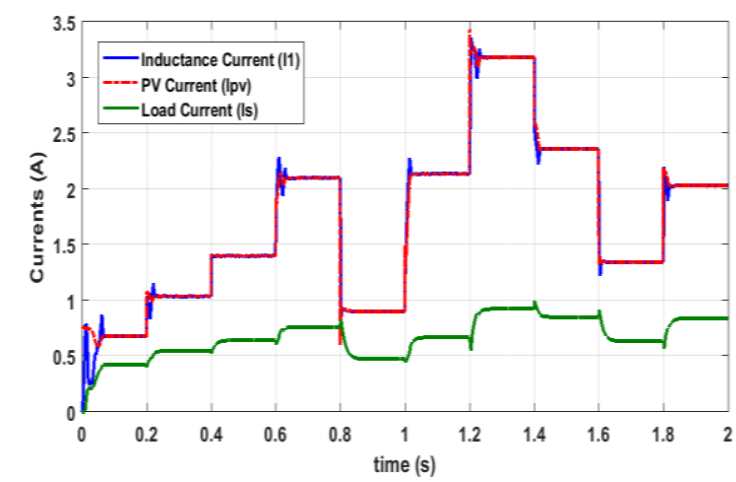

Figure 18. PV and Inductance Currents for $\mathrm{R}=50 \Omega$

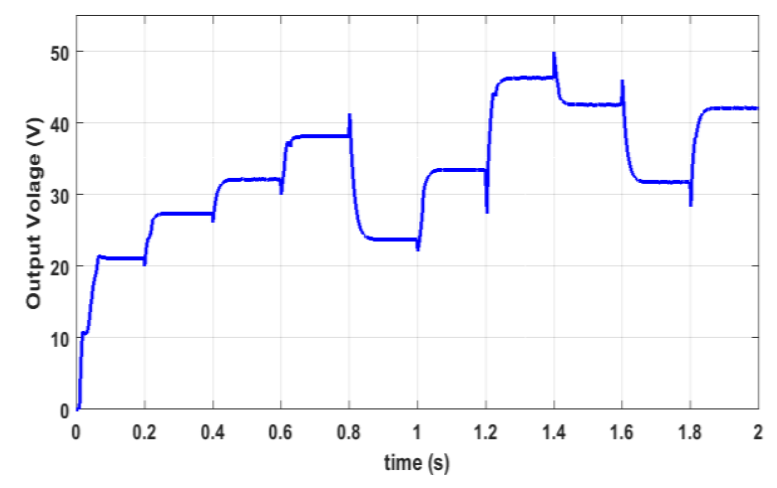

Figure 19. Output Voltage (Vs) for $\mathrm{R}=50 \Omega$

\subsection{Simulation in case of $R L E$ load type ( $R=50 \Omega, L=0.02 H$ and $E=30 \mathrm{~V}$ )}

The simulation is done assuming the same profile, as in section (6.1), of temperature and irradiance. The simulation results presented in figures as shown in Figures 20-24, also in case of RLE charge type, the control ensure good tracking of maximum power point with null ripples at steady stat.

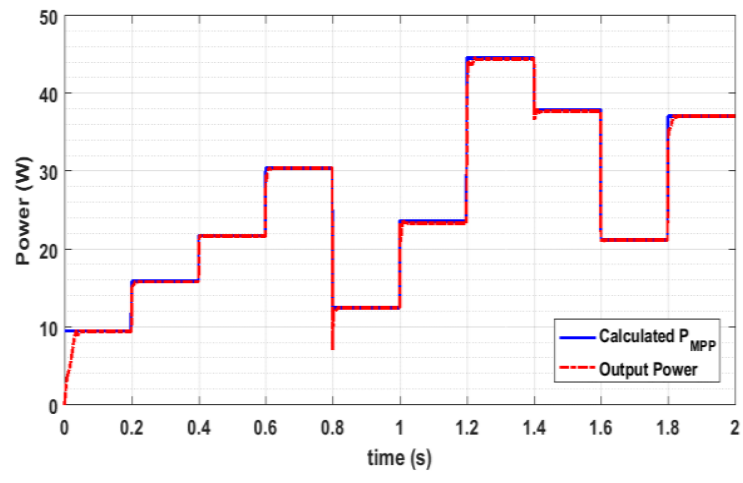

Figure 20. DC-DC Converter Output Power in case of RLE charge type

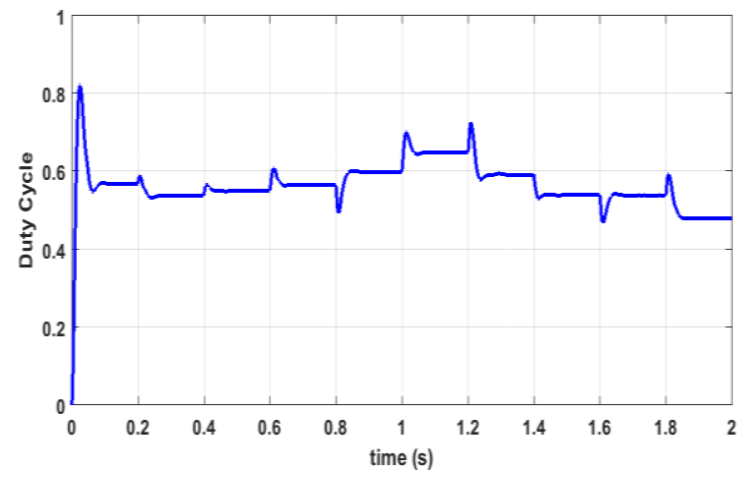

Figure 21. DC-DC Converter Duty Cycle in case of RLE charge type 


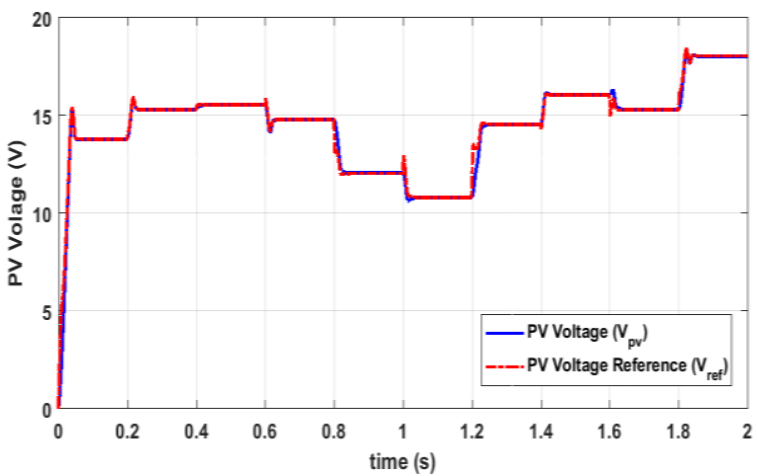

Figure 22. PV and Reference Voltages in case of RLE charge type

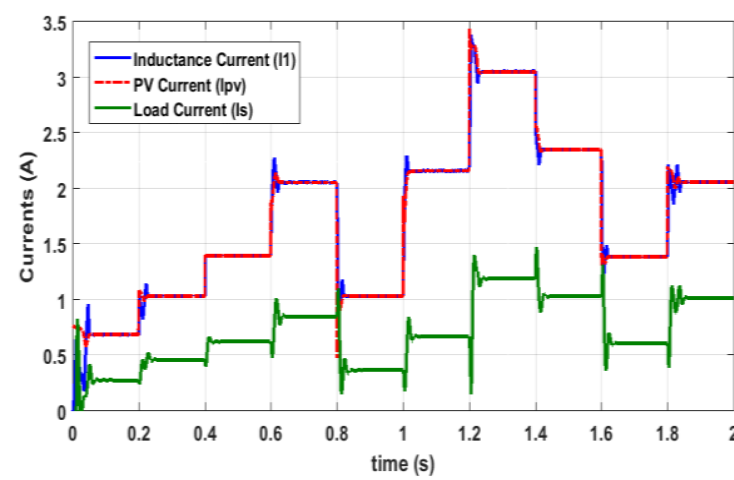

Figure 23. PV and Inductance Currents in case of RLE charge type

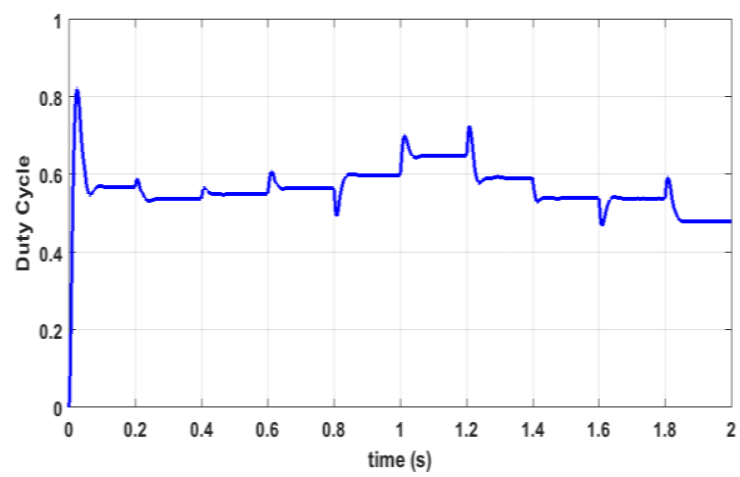

Figure 24. Duty Cycle in case of RLE charge type

\section{CONCLUSION}

In this paper we developed a control based, in first part, on MPPT Algorithm using incremental conductance principle, improved by reducing calculation time, by taking in considération voltage and current ripples and by correctly choosing Voltage reference incressing step, and in second part, on Backstepping technique to control DC-DC Boost Converter, that provide good output voltage trakcing to its voltage reference given by the MPPT Algorithm. As we have shown through simulations, this command gave good results in terms of stability, tracking quality, accuracy, and dynamic speed (with time response less than $0.02 \mathrm{~s}$ ). The validation through simulation is done assuming hard profile of atmospheric conditions variation, more than it is in real conditions (with a large variation of temperature and irradiance and a small variation duration equal to $0.1 \mathrm{~s}$ ), and it is made in case of two charges kind, in first with resistance load kind and also of a series association of resistance, inductance and voltage RLE charge type, all this simulation conditions and results proof the effectiveness of our solution of conversion and MPPT control of photovoltaic energy.

\section{REFERENCES}

[1] Renewables global status report, renewable energy policy network for the 21st century, 2018. (www.ren21.net).

[2] B. Subudhi and R. Pradhan, "A comparative study on maximum power point tracking techniques for photovoltaic power systems," IEEE Transactions on Sustainable Energy, 4(1), 89-98, 2013.

[3] N. Femia, O. Petrone, O. Spagnuolo, and M. Vitelli, "Optimization of Perturb and Observe maximum power point tracking method," Power Electronics, IEEE Transactions , pp. 963-973, 2005.

[4] W. Xiao, and W. G. Dunford, "A modified adaptive hill climbing mppt method for photovoltaic power systems," in Proc. PESC, 2004, pp. 1957-1963.

[5] N. Femia, G. Petrone, G. Spagnuolo, and M. Vitelli, "Optimization of pertub and observe maximum power point tracking method," IEEE Trans. Power Electron., vol20, no. 4, pp. 963-973, Jul. 2005

[6] K. Sundareswaran, V. Vigneshkumar, P. Sankar, S. P. Simon, P. S. R. Nayak, and S. Palani, "Development of an improved $\mathrm{P} \& \mathrm{O}$ algorithm assisted through a colony of foraging ants for MPPT in PV system," IEEE Trans. Ind. Informat., vol. 12, no. 1, pp. 187-200, Feb. 2016. 
[7] S. K. Kollimalla and M. K. Mishra, "Variable perturbation size adaptive P\&O MPPT algorithm for sudden changes in irradiance," IEEE Trans. Sustain. Energy, vol. 5, no. 3, pp. 718-728, Jul. 2014.

[8] J. Ahmed, Z. Salam, "A modified P\&O maximum power point tracking method with reduced steady-state oscillation and improved tracking efficiency", IEEE Trans. Sustain. Energy, vol. 7, no. 4, pp. 1506-1515, 2016. DOI: $10.1109 /$ tste.2016.2568043.

[9] F. Liu, Y.Kang, Y. Zhang,; S. Duan, "Comparison of P\&O and hill climbing MPPT methods for grid-connected PV converter". In Proceedings of the 2008 3rd IEEE Conference on Industrial Electronics and Applications, Singapore, 3-5 June 2008, 2011.

[10] B. N. Alajmi, K.H.Ahmed, S.J.Finney, B.W.Williams, "Fuzzy-logic-control approach of amodified hill-climbing method formaximumpower point inmicrogrid standalone photovoltaic system". IEEE Trans. Power Electron, 26, 1022-1030.

[11] Q. Shihong, M. Wang, T. Chen, X. Yao, "Comparative Analysis of Incremental Conductance and Perturb-andObservation Methods to Implement MPPT in Photovoltaic System”, Electrical and Control Engineering (ICECE) International Conference on (2011).

[12] I. P. Ratna, W. Sapto, M. Rifa'I, "Maximum Power Point Tracking for Photovoltaic Using Incremental Conductance Method", 2nd International Conference on Sustainable Energy Engineering and Application, ICSEEA 2014.

[13] Jae Ho Lee; HyunSu Bae; Bo Hyung Cho; Sch. of Electr. Eng., Seoul Nat. Univ, "Advanced Incremental Conductance MPPT Algorithm with a Variable Step Size", Power Electronics and Motion Control Conference EPEPEMC 12th International , 2006.

[14] K. Punitha, D. Devaraj, and S. Sakthivel, "Artificial neural network based modified incremental conductance algorithm for maximum power point tracking in photovoltaic system under partial shading conditions," Energy, vol. 62, pp. 330-340, 2013.

[15] A. RatnaSaxena, S. M. Gupta "Performance Analysis of P\&O and Incremental Conductance MPPT Algorithms Under Rapidly Changing Weather Conditions", Journal of electrical Systems, 292-304, 10-03-2014.

[16] A. Safari and S. Mekhilef, "Simulation and hardware implementation of incremental conductance MPPT with direct control method using cuk converter, " IEEE Trans. Ind. Electron., vol. 58, no. 4, pp. 1154-1161, Apr. 2011.

[17] R.A. Freeman, P.V. Kokotovic, "Backstepping design of robust controllers for a class of nonlinear systems", Proceedings of IFAC Nonlinear Control Systems Design Symposium, Bordeaux, France, pp. 307\{312, 1992.

[18] M. Krstic, I. Kanellakopoulos, P. Kokotovic, "Nonlinear and Adaptive Control Design," New York, Wiley, 1995.

[19] M. Moutchou et al, "Sensorless Speed Backstepping Control of Induction Machine, Based On Speed MRAS Observer," International Conference on Multimedia Computing and Systems (ICMCS'12), Morocco, IEEE Conference Publications, DOI: 10.1109/ICMCS.2012.6320166, pp. 1019-1024, 2012.

[20] Moutchou M, Abbou A, Mahmoudi H. "MRAS-based sensorless speed backstepping control for induction machine, using a flux sliding mode observer," Turkish Journal of Electrical Engineering and Computer Sciences, 23 (1), 187-200, 2015.

[21] E. Iyasere, E. Tatlicioglu and D.M. Dawson, "Backstepping PWM control for maximum power tracking in photovoltaic array systems," Proc. American Control Conference, ACC-2010, 3561-3565, 2010.

[22] T. Esram, P.L. Chapman, "Comparison of photovoltaic array maximum power point tracking techniques," IEEE Trans. Energy Conver. 22 (2) 439-449, 2007

[23] Vinoda, R. Kumara, S.K. Singhb, "Solar photovoltaic modeling and simulation: As a renewable energy solution", Energy Reports, Volume 4, Pages 701-712, November 2018.

[24] M. G. Villalva, J. R. Gazoli, E. Ruppert F, "Comprehensive approach to modeling and simulation of photovoltaic arrays", IEEE Transactions on Power Electronics, vol. 25, no. 5, pp. 1198--1208, ISSN 0885-8993, 2009.

[25] A. S. Samosir, H Gusmedi, S. Purwiyanti, E. Komalasari, "Modeling and Simulation of Fuzzy Logic based Maximum Power Point Tracking (MPPT) for PV Application," International Journal of Electrical and Computer Engineering (IJECE), Vol. 8, No. 3, pp. 1315 1323, June 2018.

[26] R. Palanisamy, K. Vijayakumar, V. Venkatachalam, R. Mano Narayanan, D. Saravanakumar, K. Saravanan, "Simulation of various DC-DC converters for photovoltaic system," International Journal of Electrical and Computer Engineering (IJECE), Vol. 9, No. 2, pp. 917 925, April 2019.

[27] A. Pradhan, B. Panda, "A Simplified Design and Modeling of Boost Converter for Photovoltaic Sytem," International Journal of Electrical and Computer Engineering (IJECE), Vol. 8, No. 1, pp. 141 149, February 2018.

Int J Elec \& Comp Eng, Vol. 10, No. 1, February 2020 : 1101 - 1112 